\title{
FOCALIZAÇÃO DAS ONDAS DE RADIO EM HF
}

\author{
WALDECIR JOÃO PERRELLA Y FERNANDO WALTER
}

Instituto Tecnológico de Aeronáutica - ITA/CTA

12.225 - São José dos Campos, SP, Brasll

\begin{abstract}
The focusing mechanisms of the HF radio waves reflected by the ionosphere are discussed. For the study of this focusing, a program of ray tracing in three dimension and the ionosphere model IRI (International Reference Ionosphere) are used. The influence of the earth's magnetic field and the horizontal gradients of the electron density are shown. Typical trajetories in the Brazilian region are shown.
\end{abstract}

\section{INTRODUÇÃO}

A perda espacial que as ondas eletromagnéticas apre. sentam na propagação no espaço livre é devido ao espalhamento da energia sobre áreas progressivamente maiores. $\mathrm{Pa}$ ra ondas se propagando na ionosfera, dependendo da refração sofrida, pode-se ter uma focalização ou desfocalização de energia.

Existem três condições nas quais os raios refletidos resultam em focalização:

i) raios com pequenos ângulos de elevação. Também chamado de focalização horizontal. Essa focalização é devido à curvatura da Terra e da base da ionosfera e aos raios que praticamente não penetram na ionosfera.

ii) raios que são recebidos próximo da região de minima distância de cobertura ("skip distance"). Essa focalização é devida aos raios que penetram na ionosfera.

iii) raios que atingem pontos antipodais. Não será estudada neste trabalho.

A desfocalização da energia ocorre devido à divergência dos raios durante sua penetração na ionosfera. Por exemplo, pode-se citar a desfocalização causada pela camada $E$ nos raios que são refletidos pela camada $F$.

Os métodos de predição ionosférica (CCIR, 1978) determinam o ganho de focalização supondo que a ionosfera é representada por um perfil de densidade eletrônica parabólico. Para se determinar a influência de outros modelamentos para a ionosfera é preciso utilizar-se da técnica de traçado de raios. Assim, neste trabalho usa-se o programa de traçado de raios desenvolvido por Perrella (1985) e os seguintes modelos para a ionosfera:

i) Usa-se o modelo do IRI (1981) para se representar a densidade eletrônica da camada F2 e o de Dudeney (1978) para as outras camadas.

ii) Os modelos de densidade eletrônica podem ou não apresentar os gradientes horizontais. Eles são obtidos através de interpolações lineares.

iii) Os modelos ionosféricos podem ou não levar em consideração a influência do campo magnético terrestre. Ele é modelado por um dipolo magnético centrado na Terra.

\section{MÉTODO}

A atenuação espacial na ionosfera pode ser obtida através da relação entre as áreas das secções transversais, no receptor e transmissor, de um feixe de raios. Mostra-se (Bradley, 1970) que a atenuação espacial $\mathrm{Pe}\left(\Delta_{\mathrm{t}}\right)$, em decibel, relativa à amplitude a uma distância unitária do transmissor, é dada por:

$\operatorname{Pe}\left(\Delta_{t}\right)=10 \log _{10}\left[R_{0} \frac{\operatorname{sen} \Delta_{r}}{\cos \Delta_{t}} \operatorname{sen}\left(\frac{D}{R_{0}}\right) \frac{d D}{d \Delta_{t}}\right]$

onde $R_{0}$ é o raio da Terra.

$\Delta_{t}$ é o ângulo de elevação do raio transmitido.

$\Delta_{r}$ é o ângulo de elevação de raio recebido $e$

D é a distância na superfície da Terra

A atenuação no espaço livre é devido ao espalhamento da energia em áreas progressivamente maiores. Ela é proporcional à distância (S) percorrida pelo raios e é expressa por:

$\mathrm{Pd}=20 \log _{10}(\mathrm{~S})$

O ganho de focalização é obtido pela diferença entre a atenuação espacial e a atenuação no espaço livre.

Neste trabalho calcula-se o ganho de focalização usando-se a técnica de traçado de raios. Resumidamente a técnica de traçado de raios consiste da resolução de um sistema de equações diferenciais com parâmetros que dependem do modelamento da ionosfera usado (densidade eletrônica e campo magnético). Desta forma, escolhendo-se uma freqüência e um ângulo de elevação para o raio transmitido, o programa determina o ângulo de elevação do raio recebido, a distância percorrida pelo raio e a distância na superfície da Terra. Para o cálculo da derivada $\mathrm{dD} / \mathrm{d} \Delta_{\mathrm{t}}$, incrementa-se o ângulo de elevação inicial e calcula-se a nova distância na superfície da Terra. Dividindo-se o incremento da distância pelo incremento angular, tem-se a derivada desejada. 


\section{RESULTADOS}

Para se estudar a influência dos vários modelamentos da ionosfera, calculou-se o ganho de focalização para vários trajetos correspondentes à região brasileira.

i) trajetórias ao longo do equador magnético

ii) trajetórias ao longo do meridiano megnético (18? Leste)

$\mathrm{Na}$ Fig. 1 tem-se os perfis das densidades eletrônicas calculados para o ponto médio dos trajetos $10^{\circ} \mathrm{N}$ e $\left.18^{\circ} \mathrm{E}\right)$.

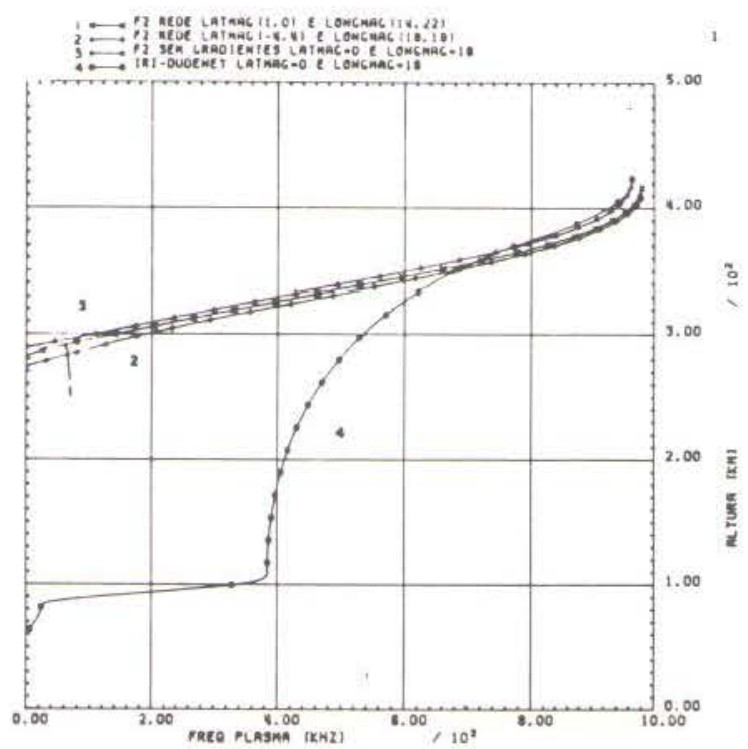

Figura 1 - Perfis das densidades eletrônicas calculadas no ponto cujas coordenadas magnéticas săo $\left.10^{\circ} \mathrm{N}, 18^{\circ} \mathrm{E}\right)$.

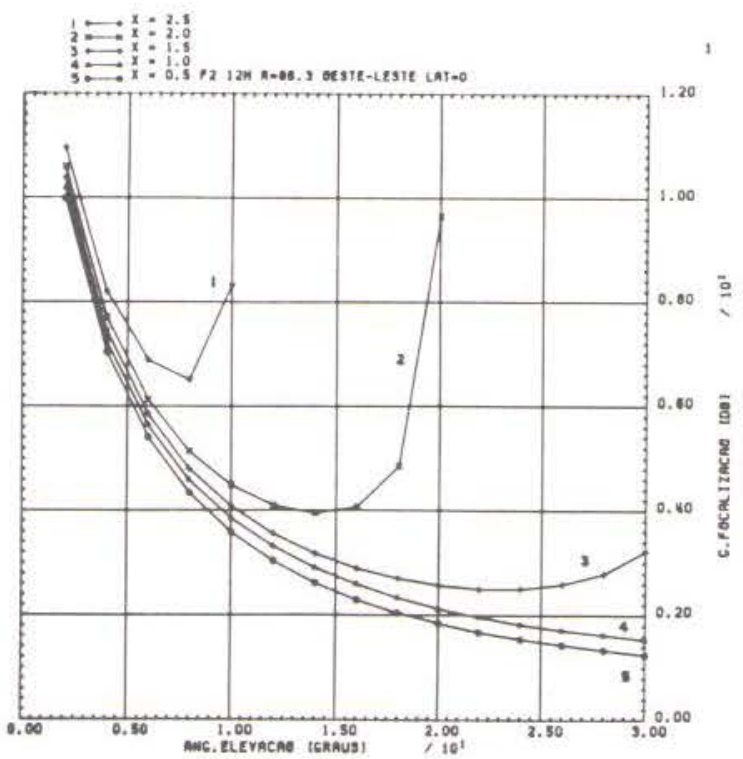

Figura 2 - Ganho de focalizaçăo. Condiçőes: 12 horas; densidade eletrônica: só a camada F2 e sem gradientes horizontais; sem campo magnético terrestre; trajetorias ao longo do equador magnético.
Na Fig. 2 tem-se os ganhos de focalização em função do ângulo de elevação e do parâmetro $x(x=f / f c$, onde $f$ é a freqüência da onda e fc é a freqüência crítica da cama. da). Pode-se notar que os ganhos de focalização correspondentes ao valor de $x=0,5$ são aproximadamente os ganhos de focalização horizontal, pois os raios são praticamente refletidos na base da ionosfera. Para outros valores de $x$ observa-se a focalização resultante de raios que penetram nessa camada. Nota-se, também, uma focalização elevada correspondente aos pontos próximos da região da distância minima de cobertura ("skip distance") e a valores de $x>1$

Na Fig. 3 tem-se os ganhos de focalização resultantes de trajetórias calculadas para as 24 horas. Houve uma diminuição de $1 \mathrm{~dB}$ nos ganhos de focalização horizontal para pequenos ângulos de elevação, devido a diminuição da altura da base dessa camada.

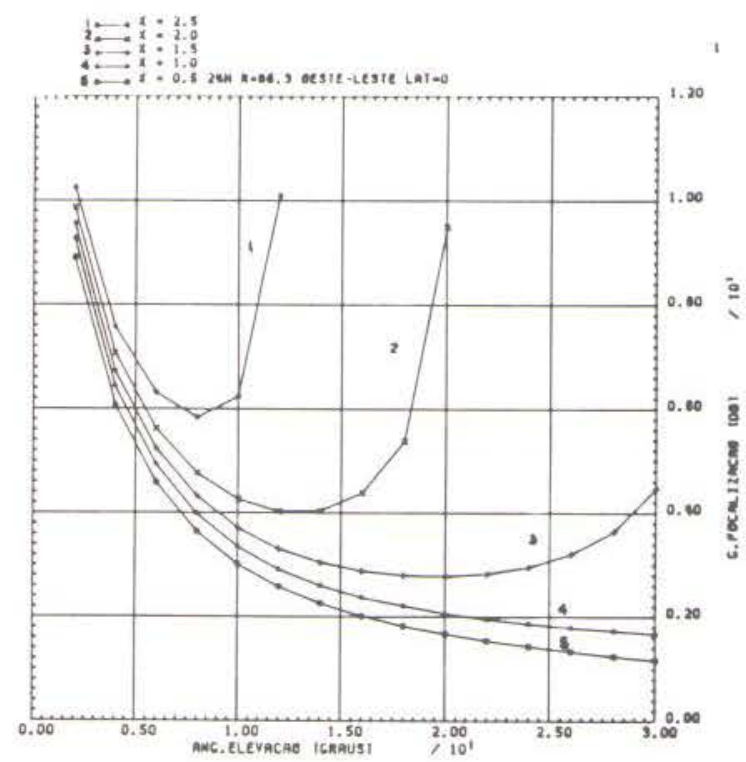

Figura 3 - Ganho de focalização

Condições: as mesmas da Fig. 2 só que referidas para as 24 horas.

Nas Figs. 4 e 5 analisa-se o ganho de focalização quando se leva em consideração o campo magnético terrestre. Nesse caso, as ondas eletromagnéticas geram duas ondas que se propagam independentemente. Devido à anisotropia do meio, a direção do raio (energia) é diferente da direção da normal à onda. A direção do raio está sempre no plano formado pelo vetor do campo magnético terrestre e do valor da normal à onda. No caso de trajetórias ao longo de um meridiano magnético os raios ordinários que penetram na ionosfera apresentam um desvio em relação à normal à onda, no sentido de se afastar da superfície da Terra. Isso faz com que os raios sejam refletidos em alturas mais altas que aquelas quando se despreza o campo magnético. Conseqüentemente os raios ordinários atingem distâncias mais longas e assim um ganho de focalização maior. A onda extraordinária tem um comportamento oposto. 


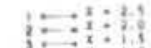

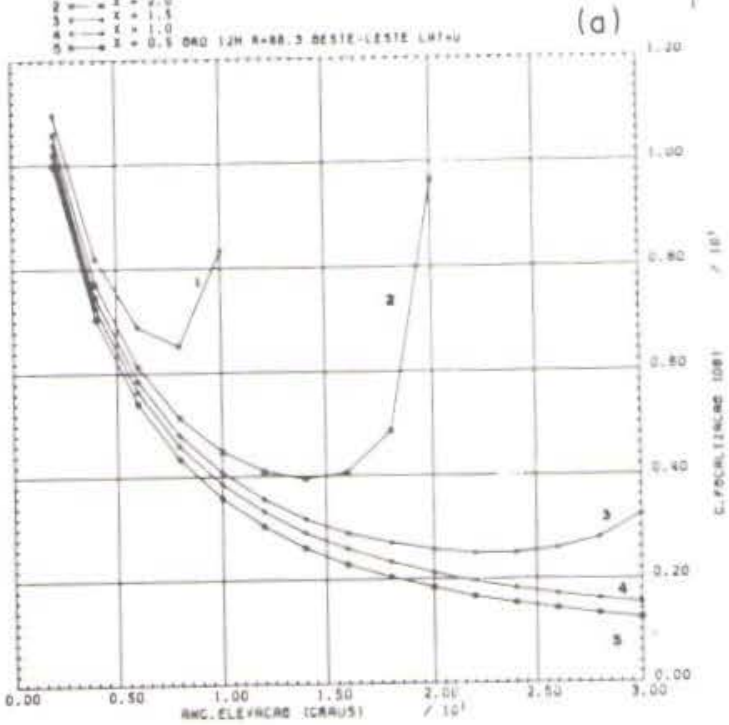

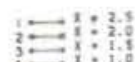

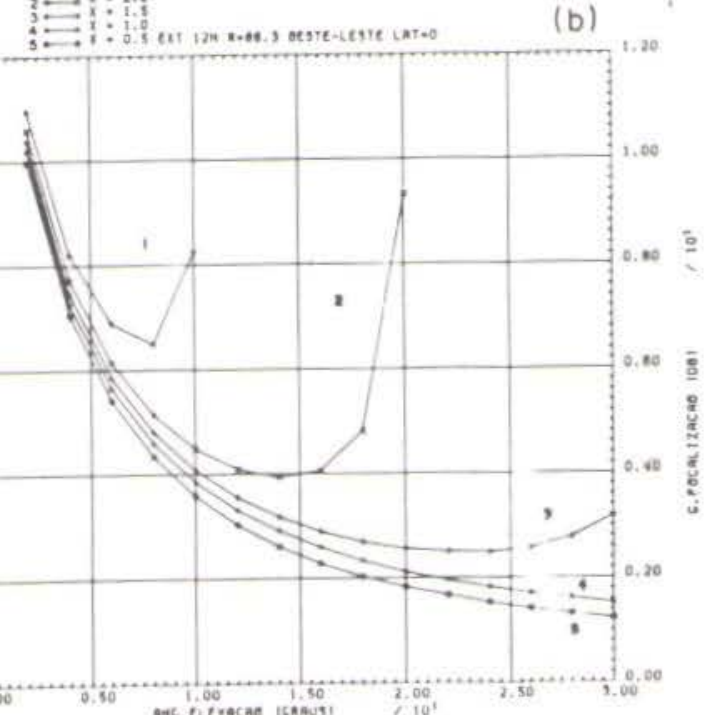

Figura 4 - Ganho de focalização

Condiçōes: 12 horas. Densidade eletrônica: só a carnada F2 e sem gradientes; com campo magnético terrestre, trajetórias ao lon go do meridiano magnético $\left(18^{\circ} \mathrm{E}\right)$

a - onda ordinária

b - onda extraordinária

Na Fig. 4 tem-se o ganho de focalização para trajetórias ao longo do meridiano $18^{\circ} \mathrm{E}$.

Observa-se nas Figs. $4 \mathrm{a}$ e $4 \mathrm{~b}$ que o efeito acima é mais pronunciado no lado direito das curvas 1, 2 e 3, as quais correspondem aos raios, que atingem as distâncias mínimas de cobertura ("skip distânce") e a valores de $x>1$.

No caso de trajetórias ao longo do equador magnétíco, os desvios dos raios em relação às normais às ondas

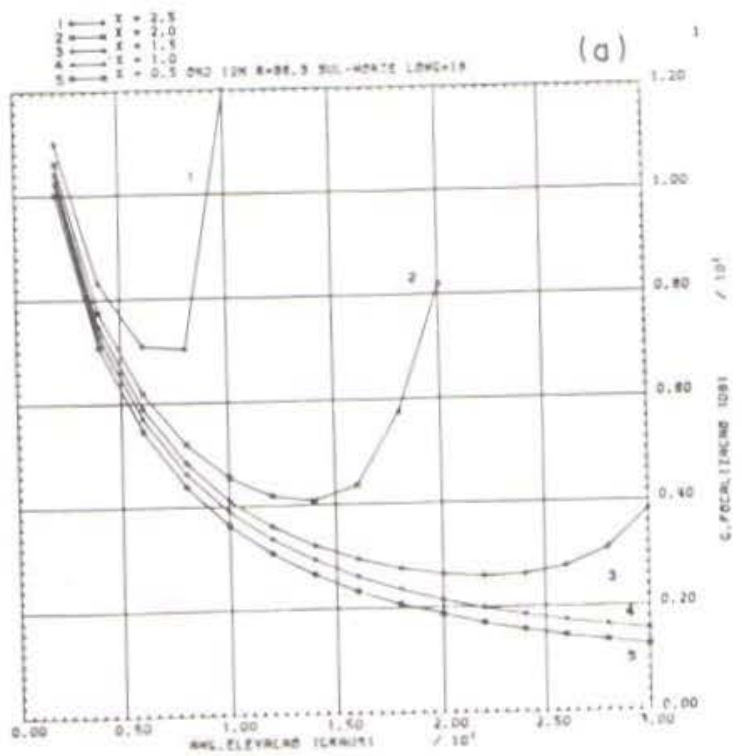

são laterais, pois devem estar nos planos que contém o ve. tor do campo magnético terrestre e da normal à onda. Esses desvios laterais não alteram o alcance dos raios e assim não são significativos para o ganho de focalização. Neste caso, as trajetórias são transversais às linhas de campo magnético e assim o índice de refração para a onda ordinária é igual ao índice de refração quando se despreza o campo magnético. Para as ondas extraordinárias e para os valores de $x$ e da giro-freqüência usados, o indice de refra.

Figura 5 - Ganho de focalização

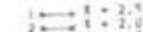

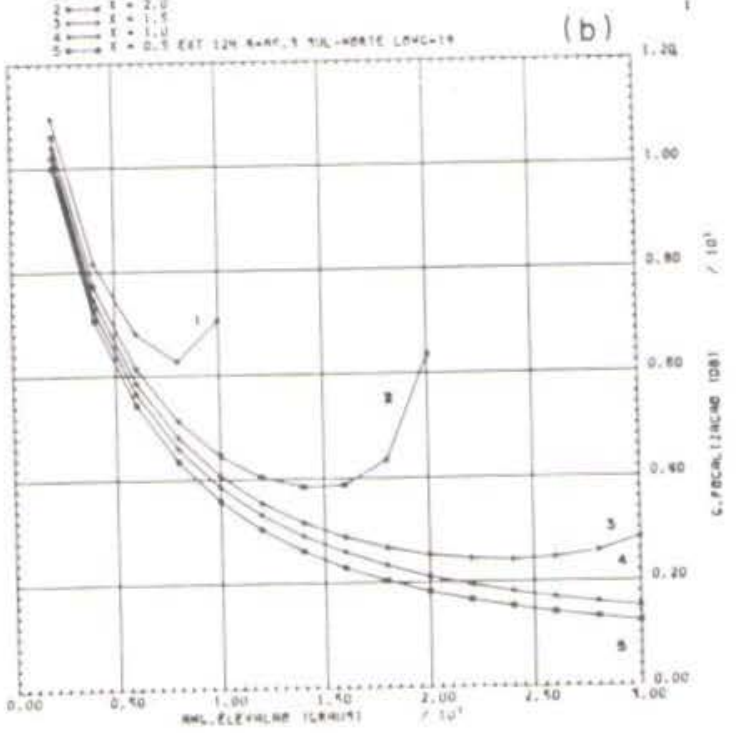

Condiçōes: as mesmas da Fig. 4, porém as trajetórias foram calculadas ao longo do equador magnético.

a - onda ordinária

b - onda extraordinária 

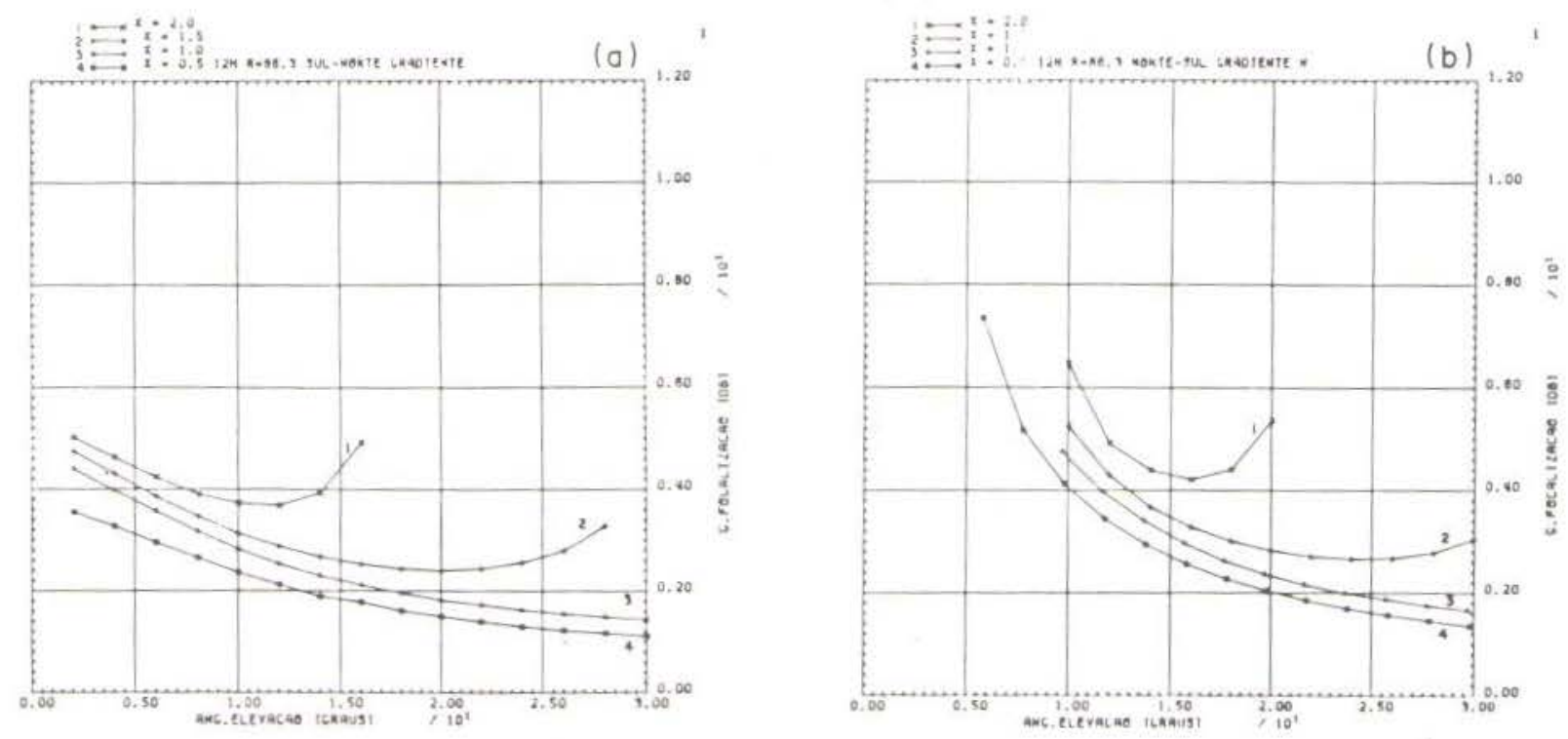

Figura 6 - Ganho de focalização

Condiçőes: 12 horas; densidade eletrónica: só a camada F2 e com gradientes; sem campo magnético; trajetórias ao longo do meridiano magnético $\left(18^{\circ} \mathrm{E}\right)$

a - sentido Sul-Norte-Gradiente positivo

b - sentido Norte-Sul-Gradiente negativo

ção não muda de maneira significativa. Assim esses raios apresentam os mesmos ganhos de focalização que os raios obtidos quando se despreza o campo magnético. Na Fig. 5 tem-se os ganhos de focalização para as ondas ordinárias e extraordinárias em trajetórias ao longo do equador magnético e, assim, comprova-se as afirmaç̃es acima.

$\mathrm{Na}$ Fig. 6 tem-se os ganhos de focalização resultantes de trajetórias longitudinais e com um modelo de densidade eletrônica com gradientes horizontais. Na Fig. 6a têmse os ganhos de focalização resultantes de trajetórias no sentido Sul-Norte e, na Fig. 6b, no sentido oposto. Neste caso, o gradiente horizontal importante é o gradiente da densidade eletrônica em relação às colatitudes. Verificou-se que esse gradiente é negativo. Assim, as trajetórias no sentido Norte-Sul enfrentam gradientes negativos e devido a isso os raios são recebidos com ângulos de eleva. ção menores tornando os trajetos mais longos. Para as trajetórias Sul-Norte, os raios enfrentam gradientes horizontais positivos, de modo que os raios são recebidos com ângulos de elevação maiores, tornando os trajetos mais cur-

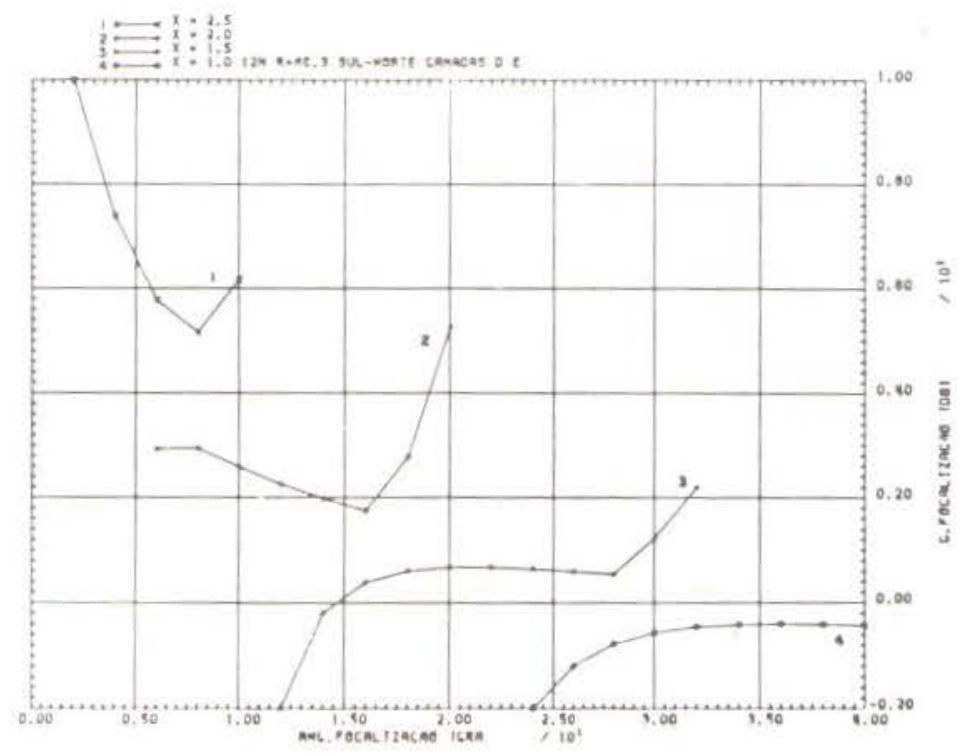

Figura 7 - Ganho de focalizaçăo

Condições: 12 horas; densidade eletrônica: com todas as camadas (D, E, F2) e sem gradientes; sem campo magnético; trajetória ao longo do meridiano magnético $\left(18^{\circ} \mathrm{E}\right)$. 
tos. Assim, essas trajetórias Norte-Sul apresentam ganhos de focalização maiores que as trajetórias Sul-Norte.

$\mathrm{Na}$ Fig. 7 tem-se os ganhos de focalização para um modelo de densidade eletrônica com todas as camadas. Para a região $E$ e $F$ usou-se o perfil do modelo de Dudeney (1978). Pode-se observar que para pequenos valores de $x$ tem-se uma desfocalização bastante acentuada provocada pela camada E. Observa-se também que, para pequenos ângulos de elevação os raios não furam a camada $E$. Para finalizar, observa-se que para grandes valores de $x$ a diferença entre os ganhos de focalização e os da Fig. 2 começam a diminuir, chegando a ser menores que $1 \mathrm{~dB}$ para $x>2,5$.

\section{CONCLUSOES}

Calculou-se o ganho da focalização para ondas via ionosfera através do programa de traçado de raios a três dimensões em conjunto com vários modelos ionosféricos (densidade eletrônica com ou sem gradientes horizontais, com ou sem a presença das camadas inferiores e com ou sem a presença do campo magnético terrestre).

\section{BIBLIOGRAFIA}

BRADLEY, P.A. - 1970 - Focusing of radio waves reflected from the ionosphere at low angles of elevation. Electronics Letters, $6:$ : $457-458$.

CCIR - 1978-Interim method for estimating sky wave field strength and transmission loss at frequencies between 2 e 30 $\mathrm{MHz}$. CCIR Supplement to report 252-2. Doc. 6/1070-E, Kyoto, March.

DUDENEY, J.R. - 1978 - An improved model of the variation
A influência desses modelamentos no ganho de focalização pode ser resumida em:

i) o ganno da focalização aumenta com o aumento da base na camada refletora para um dado $\mathrm{x}$ e um dado ângulo de elevação.

ii) o campo magnético não apresenta uma influência significativa nos trajetos transversais ao campo magnético. Nos trajetos longitudinais ao ganho de focalização aumenta para as ondas ordinárias e diminui para as ondas extraordinárias. Esse efeito é mais significativo (1 dB) para os trajetos próximos da região de mínima distância de cobertura.

iii) para um dado ângulo de elevação e um dado $x$, o ganho de focalização aumenta quando os trajetos enfrentam gradientes horizontais da densidade eletrônica negativos e diminui quando enfrentam gradientes positivos.

iv) a presença das camadas inferiores provoca uma desfocalização significativa nas ondas com baixos valores de $x(x<2)$ e que são refletidas pela camada superior. Para valores grandes $x(x>2,5)$ as desfocalizações são menores que $1 \mathrm{~dB}$ quando comparadas com os ganhos de focalização desprezando-se as camadas inferiores. of eletron-concentration with height in the ionosphere. J. Atmos. Terr. Phys., 40: 195-203.

IRI - 1981 - International reference ionosphere. World Data Center for a Solar Terrestrial Physics. Report UAG - 82, november.

PERRELLA, W.J. - 1985 - Análise dos parâmetros de circuitos de HF com modelamento da ionosfera usando a técnica de traçado de raios. Tese de Doutorado, ITA, S.J.Campos - SP. 